A framework for understanding Supplemental Instruction is presented along with theoretical and philosophical underpinnings.

\title{
Understanding the Supplemental Instruction Model
}

\author{
David R. Arendale
}

\section{Overview of Supplemental Instruction}

Supplemental Instruction (SI) is a student academic assistance program that increases academic performance and retention through its use of collaborative learning strategies. The SI program targets traditionally difficulty academic courses, those that typically have 30 percent or higher rate of $D$ or $F$ final course grades or withdrawals, and provides regularly scheduled, out-of-class, peer-facilitated sessions that offer students an opportunity to discuss and process course information (Martin, Lorton, Blanc, and Evans, 1977).

High-Risk Courses Versus High-Risk Students. SI thus avoids the remedial stigma often attached to traditional academic assistance programs, since it does not identify high-risk students but identifies high-risk classes. SI is open to all students in the targeted course; therefore, prescreening of students is unnecessary. Since the SI program begins the first week of the academic term, the program provides academic assistance during the critical initial sixweek period of class before many students face their first major examination. Attrition is highest during this period (Blanc, DeBuhr, and Martin, 1983; Noel, Levitz, and Saluri, 1985).

Historically difficult or high-risk courses often share the following characteristics: large amounts of weekly readings from both difficult textbooks and secondary library reference works, infrequent examinations that focus on higher cognitive levels of Bloom's taxonomy, voluntary and unrecorded class attendance, and large classes in which each student has little opportunity for 
interaction with the professor or the other students. Sl is often attached to traditionally difficult, high-risk courses that serve first- and second-year students. Several institutions report the successful use of SI with students in graduate and professional schools (Bridgham and Scarborough, 1992; Martin and Arendale, 1992; Martin, 1980). However, each institution may develop its own definition of high-risk courses.

Such a designation of high-risk for a course makes no prejudicial comment about the professor or the students. It is a numerical calculation that indicates a sizeable number of students have difficulty in meeting academic requirements for the class. Rather than blaming the students or the professor, the designation suggests that additional academic support is needed for students to raise their level of academic performance to meet the level deemed appropriate by the classroom professor. In recent years, the popular and professional literature has been replete with extensive discussions about who is at fault for the perceived lower quality of student academic achievement. SI bypasses this issue and provides a practical solution that helps students meet the professor's level of expectation.

Proactive Assistance Before Problems Occur. Assistance begins in the first week of the term. The SI leader introduces the program during the first class session and surveys the students to establish a schedule for the SI sessions. Attendance is voluntary. Students of varying abilities participate, and no effort is made to segregate students based on academic ability. Many underprepared students who might otherwise avoid seeking assistance will participate in SI since it is not perceived to be remediation and there is no stigma attached. Such stigma can cause motivation problems for developmental students (Somers, 1988).

SI enables students to master course content while they develop and integrate effective learning and study strategies. Therefore, learning/study strategies (for example, note-taking, organization, test preparation) are integrated into the course content during the SI sessions. Immediate practice and reinforcement of these acquired skills are provided. SI collaborative sessions capitalize on the use of the "teachable moment" to apply the learning strategies to the course material. Educational researchers (Dimon, 1988; Keimig, 1983; Stahl, Simpson, and Hayes, 1992) have concluded that it is difficult to teach transferable study skills in isolation from content material.

Features of SI That Contribute to Student Success. Several features of the SI model operate to influence higher levels of student academic performance. The impact of Supplemental Instruction can be quantified by positive differences in student performance and retention rates. The following factors are most often mentioned by $\mathrm{SI}$ staff as well as by participating faculty and students (Martin and others, 1983)

The service is proactive rather than reactive. SI schedules are set during the first week of class, allowing students to obtain assistance before they encounter academic difficulty. Most "early alert" retention programs are not triggered until the student has already earned a " $D$ " or " $F$ " on a major examination. 
The service is attached directly to specific courses. Reading, learning, and study skills instruction are offered in the context of course requirements and as an outgrowth of student questions and concerns. Thus instruction has immediate application. While many students may self-report their need for academic assistance, only a small group will voluntarily attend workshops that feature instruction in isolated study skills.

SI leaders attend all class sessions. Such attendance contrasts sharply with the more common tutorial practice of providing instruction based largely upon the student's perceptions of what occurred in class. Student perceptions are often distorted as well as time-consuming to report during the academic assistance sessions.

By design, $\mathrm{SI}$ is not a remedial program. Although $\mathrm{SI}$ is effective with underprepared students, it is not viewed as remedial. The students who are most likely to volunteer initially are those who tend to be better prepared academically. The willingness of this group to participate encourages the participation of less able students who often find it difficult to admit that they need assistance.

SI sessions are designed to promote a high degree of student interaction and mutual support. Such interaction leads to the formation of peer study groups and facilitates the mainstreaming of culturally diverse as well as disadvantaged students. SI has relied upon the power of group study for the past twenty years, long before the current trend of promoting collaborative learning groups in higher education.

SI provides an opportunity for the course instructor to receive useful feedback from the SI leader. Students generally hesitate to be candid about academic concerns to course instructors for fear of demeaning themselves or offending the professor. They will, however, openly acknowledge their problems to the SI leader. The duty of the SI leader is to listen to their comments and then to redirect the students toward developing strategies to cope with the situation. The SI leader is not to assess the course professor or agree or disagree with student comments. If the course professor has previously invited feedback from the SI leader, the SI leader shares student comments or concerns in a nonthreatening and anonymous fashion, privately with the course instructor.

When SI May Be Less Effective. While success varies among and between SI programs, we have no data that would suggest any major limitations in SI. We do know, however, that conducting $\mathrm{SI}$ is more challenging in content areas where prerequisite skills are a key variable.

For example, if students do not remember any algebra, they will have a particularly difficult time in chemistry. SI can be and is effective in these areas. However, SI leaders must invest more time in planning. SI sessions often need to last longer than fifty minutes to cover additional material and provide additional time for students to practice and master the course material and study strategies. Additionally, SI groups may need to be reorganized to ensure that leaders who review the basics of algebra do not bore the more mathematically able students. 
Our experience has been that SI is least effective when it is attached to remedial classes. First, students may refuse to attend SI sessions if they do not perceive the course to be demanding. Second, SI has not been effective for students who cannot read, take lecture notes, write, or study at the high school level. Therefore, we stress that adopting institutions use SI in nonremedial settings with high-risk, demanding courses.

We have also found that the SI model needs to be slightly modified in courses that are problem-based and involve practice for mastery. In those circumstances, SI sessions need to be more frequent and sometimes longer. For example, a three-credit-hour accounting course might require sufficient SI sessions to allow for the review of various types of problems, or a calculus class might require extended sessions to allow time for modeling and practice so that students become proficient problem solvers.

Key SI Program Personnel. Key people involved with SI on each campus include the SI leaders, the SI supervisor, and the course instructors. Each plays an important role in creating the environment that allows the Sl program to flourish.

With the increasing diversity in the college classroom and in the level of student academic preparedress, institutions are seeking to develop a community of learners. SI helps promote the formation of such communities and promotes scholarship through increased academic performance and retention of students. Faculty enjoy the resources and support provided by the SI leader.

The SI leader. The SI leader is a student who has successfully completed the targeted class or a comparable course. It is ideal if the student has taken the course from the same instructor for whom he or she is now providing SI assistance. The SI leader is trained in proactive learning and study strategies and operates as a "model student," attending all course lectures, taking notes, and reading all assigned materials. The SI leader conducts three or more outof-class SI sessions per week during which he or she integrates "how to learn" with "what to learn" (Martin and others, 1983).

The SI leader is a facilitator, not a mini-professor. The role of the leader is to provide structure to the study session, not relecture or introduce new material. The SI leader should be a "model student" who shows how successful students think about and process course content. He or she facilitates a process of collaborative learning, an important strategy since it helps students to empower themselves rather than remain dependent as they might in traditional tutoring. Research suggests that tutoring relationships do not always promote transfer of needed academic skills (Blanc, DeBuhr, and Martin, 1983; Dimon, 1988; Keimig, 1983; Martin and Arendale, 1990, 1992; Martin and Gravina, 1990; Martin and others, 1983; Martin and Blanc, 1981; Martin, 1980; Martin, Lorton, Blanc, and Evans, 1977; Maxwell, 1990).

A central responsibility of the SI leader is to integrate study skills with the course content. As someone who has performed well in the course, the SI leader has displayed mastery of the course material. However, it is important that the SI leader share his or her learning strategies with the other students in 
the SI sessions. If the students learn only content material and not the underlying study strategies, they will have a high probability of experiencing academic difficulty in succeeding courses.

The integration of study skills with the course content is a key difference between SI and other forms of collaborative learning. It is not just that students are working together; rather, it is the planned integration and practice of study strategies that sets SI apart. We believe that by combining what to learn with how to learn it, students are able to develop both content competency and transferable academic skills that pay off in higher grades during future academic terms.

The SI supervisor. The SI supervisor is an on-site professional staff person who implements the SI program and supervises the SI leader. The supervisor is responsible for identifying the targeted courses, gaining faculty support, selecting and training leaders, and monitoring and evaluating the program. Supervisors meet with SI leaders weekly during the term as a group or individually. Supervisors of most programs have formal meetings with all SI leaders together at least three times during the term for follow-up and problem solving.

SI supervisors attend a three and one-half day training workshop covering the areas of implementation and management, training, supervision, evaluation, and study strategies. Continued professional development is available through professional development seminars.

The faculty member. The third key person in implementing SI is the faculty member who teaches the course in which SI is offered. Faculty screen SI leaders for content competency. SI leaders are encouraged to meet weekly with SI course faculty members during their office hours to discuss SI session activities. Faculty cooperation is an essential ingredient of the SI model; therefore, SI is only used in classes where professors understand and support the idea. This policy holds true even if department chairs and deans request that SI be attached to certain classes.

While regular meetings are encouraged, faculty are free to choose their level of involvement with the SI leaders and the program supervisor. Some faculty members choose to meet with the SI leader to plan for SI sessions. This may include the creation of work sheets, mock examinations, or other materials. Many other faculty also request that the SI leader provide anonymous feedback from students concerning difficulties encountered during class lectures or with the reading materials. On the other hand, some faculty choose not to devote additional time to the program.

The SI program staff makes every effort to be supportive of the professor. This support might include checking the bookstore to see that the number of textbooks is sufficient to accommodate the number enrolled; calling students who are absent; checking materials on reserve in the library; and handing out materials during class. The only restrictions placed on SI leaders are that they may not share the SI session attendance sheets nor help create or grade course examinations. 


\section{Creating Awareness and Generating Support for SI on Campus.}

Gaining acceptance for any new student support program has historically been a difficult undertaking, especially in times of limited resources. Additionally, since the impetus for new academic support programs often comes from administrators or student affairs staff, there is the risk of potential opposition among the faculty.

Our experience (Martin and others, 1983), as well as reports from other institutions that have adopted SI, lead us to the following four suggestions for generating on-campus program support:

It is essential, our experience demonstrates, that facilitators receive training in the use of the SI program. While the basic tenets of SI programs are relatively simple, integration of course content review with study strategy practice and implementation is more complex. Issues and activities often covered during training workshops include mock SI session participation, SI session supervision, SI leader training topics, data collection and analysis activities, strategies to promote the SI program, and other practical issues related to program implementation and growth.

Such workshops are held in Kansas City and at a variety of locations across the United States, providing an opportunity to not only receive helpful training, but also to meet with other institutions that are also present for the workshop. SI has continued to grow and evolve for the last two decades in part because of the interaction between other adopting institutions.

Our second recommendation for generating on-campus support is to have a pilot program approach to starting $\mathrm{SI}$. The best way to generate on-campus support is to have a successful pilot in place. Faculty members who have had positive experiences with SI become the program's strongest advocates.

We advise adopting institutions to begin a pilot program by eliciting the support of one or two faculty members who are well respected by their peers and teach entry level courses that are traditionally difficult for students. These faculty should have reputations as excellent instructors who have both rigorous and fair grading standards. They should also be willing to assign a higher than normal distribution of $A, B$, and $C$ grades if students display increased levels of performance on examinations.

Our final suggestion for generating support for SI concerns the data collected. After conducting the pilot program, it is critical to prepare and disseminate final reports on the outcomes. Part of the attraction of SI to administrators and faculty members is the analysis of hard data-final course grades of SI participants compared with nonparticipants. Such reports are also helpful in presenting the findings to other faculty who may be interested in attaching SI to their courses. We suggest that faculty be approached individually, in small groups, or in departmental meetings. The SI supervisor should invite the instructors who were involved in the pilot to be part of these presentations. 
When Supplemental Instruction has been carried out on other campuses without a pilot program to generate initial on-campus support (for example, when SI has been mandated by an administrator), the service has proven less than successful. Once faculty concerns are made public, they are difficult to address adequately, and attempts to do so are often viewed with skepticism. On the other hand, if SI is willingly piloted with a school or department, the program will generate its own support. One final note: while the UMKC SI program has not been a success with all students who have tried it, we have yet to lose a single faculty member!

\section{Different Approaches to Assisting Students}

Robert Blanc, associate professor and curriculum specialist for the School of Medicine at the University of Missouri-Kansas City, should be credited with the conceptual framework for comparing and contrasting the traditional (medical) and nontraditional approaches to assisting students.

Traditional Approaches to Assisting Students. Traditional individual tutorial practices may be described as following a medical model: an individual is identified as needing professional assistance on the basis of (a) prior history and diagnostic testing, (b) self-referral in response to perceived symptoms, or (c) referral by another professional in response to observed symptoms.

In some institutions, identification of high-risk students is based primarily on prior history of test scores (a). These tertiary institutions are likely to be somewhat selective, requiring students to submit to extensive prematriculation testing and interviews. Professional schools and private, selective colleges are among those fitting this category. Students entering such institutions typically commit for the long term and; at a minimum, can be expected to persist for a year. Under these circumstances, academic therapy with students at risk can begin immediately upon matriculation and can continue until students give evidence of being able to function independently in the academic environment.

As noted (b), some students voluntarily seek assistance. Their symptoms in these instances may range from free-floating anxiety in the academic setting to unsatisfactory performance in one or more highly specific settings. The tutor or resource specialist must function first as diagnostician, identifying the basis for the students' self-referral and differentiating between anxiety and a variety of other reasons for unsatisfactory performance. Having established at least a tentative diagnosis, the tutor then becomes the therapist, helping students to negotiate the academic demands of the institution.

Finally, another professional, usually a professor or graduate teaching assistant, may become aware that a student is in academic difficulty (c). This awareness may come in a variety of ways, most likely in the wake of unsuccessful performance on an academic task. For example, the faculty member may refer the student for tutorial assistance to correct an academic problem 
apparent because of a low test score. In this instance, the tutor functions, as described previously; first as a diagnostician and then as a therapist.

Rationale for a Nontraditional Approach. It was in a milieu dominated by tutorial services in the medical model that SI developed. The developers at UMKC found that several assumptions of the medical model either did not apply or were not practiced in their institution. Subsequent adoption of SI on other campuses may suggest that the same assumptions were found wanting on these other campuses as well.

As noted, the traditional model relies on identification of the "high-risk" student, the student deemed deficient or "at-risk" in some way. In institutions other than those described, that is, selective tertiary and professional schools, several factors preclude such prematriculation identification.

First, the faculty and staff must know entering students in time for key personnel to establish contact with at-risk students. Second, they must note in this context that neither prior performance nor standardized testing is sufficiently reliable as a prediction criterion of who is and is not at-risk. As many as 50 percent of those whose prior scores suggest they are at-risk prove to be successful without intervention, and many of those who are not identified in this manner prove to be unsuccessful.

Analyses of high school grades and standardized college entrance examinations do not identify all students who will drop out of college for academic reasons (Blanc, DeBuhr, and Martin, 1983; Christie and Dinham, 1991; Martin and others, 1983; Tinto, 1987), and attrition cannot be addressed effectively by providing help only to those students who show either symptoms or predisposing weaknesses. The treatment must be more generalized, and the problem must be addressed at or near its source: the mismatch between the level of instruction and the level of student preparation (Martin, Lorton, Blanc, and Evars, 1977).

Timely identification of students who are at-risk is difficult in the traditional model. Faculty who can refer students for corrective instruction are rarely able to make a referral before the scoring of the first course examination. Students who are referred after that time are at a considerable disadvantage, trying to catch up with the class after a very poor start. The rate of student attrition across courses is greatest in the first six weeks or after the first exam when students may find their grades disappointing (Blanc, DeBuhr, and Martin, 1983; Noel, Levitz, and Saluri, 1985).

Students who are at risk are among those least compliant with faculty recommendations for special help, whether for personal counseling or for academic assistance. Such students often perceive that tutorial help, far from relieving them of their academic burden, increases the burden as they must now answer to a tutor in addition to the course professor.

Finally, students who are at risk are notorious for their reluctance to refer themselves for assistance until much too late. Whether through denial, pride, or ignorance, students who need help the most are least likely to request it. So goes the axiom of the learning assistance trade (Somers, 1988). 
SI first developed in an institution that did not fit into the medical model described previously in this chapter. At UMKC, students can register as late as the first day of class, with their prior transcripts and test score data to be submitted sometime before the beginning of the following semester. This large, inner-city, commuter institution typically turned over 40 percent of its students each semester, most of them due to transfer but some due to the phenomenon now known as "stopping out" as distinguished from "dropping out." "Stopping out ${ }^{n}$ refers to the widespread practice of taking no classes during a semester that would be devoted to other priorities, such as working to reestablish a bankroll sufficient to allow subsequent reentry.

Delivery of services from the first day of class changes the support program from a reactive to a proactive mode. One of the noncognitive variables that differentiates between more capable and less capable students is this: those who are less capable are inclined to do without support services until they need them; those who are more capable will avail themselves of services at the beginning and stop services if they find the services to be neither productive nor essential. The presence of these more capable students in support sessions affirms that the sessions are not remedial. That fact enables less capable students to participate without the fear of stigma.

The integration of skills and content allows the SI leader to meet the perceived content needs of students while delivering essential skills instruction simultaneously. If, as McLuhan argued, "the medium is the message," then the message of SI is skill instruction, delivered along with the course content material.

Delivering services on an outreach basis, that is, in the classroom buildings assigned for regular academic instruction, lends an air of academic credibility to the support service. Similarly, the overt endorsement of the SI program from the participating course professor lends further authority to the claim that SI is valuable.

Of course, the voluntary nature of the SI pact which is renewable every week (or every day, for that matter) comforts the wary student who shuns taking on additional responsibility. The combination of voluntary participation, early intervention, and proactive support differentiates the SI model from the traditional medical model that relies on diagnosis of signs and symptoms followed by prescriptive treatment.

\section{Conclusion}

It has been nearly two decades since Supplemental Instruction first appeared in higher education. After starting at the University of Missouri-Kansas City in 1973, SI has been implemented at a variety of institutions across the United States and around the world. Borrowing ideas from developmental psychology, SI has attempted to encourage students to become actively involved in their own learning. By integrating appropriate study skills with the review of the course content, students begin to understand how to use the learning 
strategies they have heard about from teachers and advisors. As new educational theories and practices have surfaced, the SI model has been adapted to incorporate the best in educational research.

With the increasing diversity of today's college students and the advent of alternative admission programs, the student body is continuing its evolution into a heterogeneous group reflective of American society. The popular and professional literature often carries articles decrying the poor academic preparation level of students or the poor quality of teaching by classroom professors. Few solutions have been offered that work. From our point of view, the matter is moot. Many professors have tenure and colleges need all the students that they can recruit. Rather than blaming either party, strategies must be developed that allow students to succeed while ensuring that academic standards are maintained, if not strengthened. SI, as one component, can contribute to an overall institutional plan for student success.

\section{References}

Blanc, R. A., DeBuhr, L., and Martin, D. C. "Breaking the Attrition Cycle: The Effects of Supplemental Instruction on Undergraduate Performance and Attrition." Joumal of Higher Education, 1983, 54 (1), 80-89.

Bridgham, R. G., and Scarborough, S. "Effects of Supplemental Instruction in Selected Medical School Science Courses." Academic Medicine RIME Supplement, 1992, 67 (10), 569-571.

Christie, N. G., and Dinham, S. M. "Institutional and External Influences on Social Integration in the Freshman Year." Journal of Higher Education, 1991, 62, 412-436.

Dimon, M. "Why Adjunct Courses Work." Journal of College Reading and Learning, 1988, 21, 33-40.

Keimig, R. I. Raising Academic Standards: A Guide to Learning Improvement. ASHE-ERIC Higher Education Report, no. 4, Washington, D.C.: Association for the Study of Higher Education, 1983. (ED 233 669)

Martin, D. C., and Arendale, D. (eds.). Supplemental Instruction: Improving First-Year Student Success in High-Risk Courses. Columbia, S.C.: National Resource Center for the Freshman Year Experience, 1992.

Martin, D. C., and Arendale, D. "Supplemental Instruction: Improving Student Performance, Increasing Student Persistence," 1990. (ED 327 103)

Martin, D. C., and Gravina, M. "Serving Students Where They Fail: In Class." Thresholds of Education, Aug. 1990, 26, 28-30.

Martin, D. C., Blanc, R. A., DeBuhr, L., Alderman, H., Garland, M., and Lewis, C. Supplemental Instruction: A Model for Student Academic Support. Kansas City, Mo.: University of Missouri and ACT National Center for the Advancement of Educational Practices, 1983.

Martin, D. C., and Blanc, R. A. "The Learning Center's Role in Retention: Integrating Student Support Services with Departmental Instruction." Joumal of Developmental Education, 1981, 4, 2-4, 21-23.

Martin, D. C. "Learning Centers in Professional Schools." K. V. Lauridsen (ed.), New Directions for College Learning Assistance: Examining the Scope of Learning Centers. San Francisco: Jossey-Bass, 1980.

Martin, D. C., Lorton, M., Blanc, R. A., and Evans, C. The Learning Center: A Comprehensive Model for College and Universities. Kansas City, Mo.: University of Missouri, 1977. (ED 162 294)

Maxwell, M. "Does Iutoring Help? A Look at the Literature." Review of Research in Developmental Education, 1990, 7 (4), 1-5. 
Noel, L., Levitz, R., and Saluri, D. (eds.). Increasing Student Retention: Effective Programs and Practices for Reducing the Dropout Rate. San Francisco: Jossey-Bass, 1985.

Somers, R. L. Causes of Marginal Performance by Developmental Students. Boone, N.C.: National Center for Developmental Education, Appalachian State University, 1988.

Stahl, N. A., Simpson, M. L., and Hayes, C. G. "Ten Recommendations from Research for Teaching High-Risk College Students." Joumal of Developmental Education, 1992, 16 (1), $2-4,6,8,10$.

Tinto, V. Leaving College: Rethinking the Causes and Cures of Student Attrition. Chicago: University of Chicago Press, 1987.

DAVID R. ARENDALE is national project director for Supplemental Instruction and associate director of the Center for Academic Development at the University of Missouri-Kansas City. 